Antonia Ma Ortiz Ballesteros

AMaria.Ortiz@uclm.es

Universidad de Castilla La Mancha

(Recibido: 26 mayo 2018/ Received: 26 $6^{\text {th }}$ May 2018 (Aceptado: 11 octubre 2018 / Accepted: 11 ${ }^{\text {th }}$ October 2018)

\section{HISTORIAS DE SIEMPRE PARA LECTORES DE HOY: LA RECEPCIÓN INFANTIL DE LA FÁBULA DE LA TORTUGA Y LOS PATOS}

\author{
OLD STORIES FOR TODAY'S READERS: CHILDREN'S \\ RECEPTION OFTHE TORTOISE AND THE DUCKS \\ FABLE
}

\title{
Resumen
}

La fábula ha sido tradicionalmente uno de los géneros destinado a los niños por su sencillez, sus protagonistas y sus posibilidades didácticas. Desde sus origenes, ha ido cambiando para acomodarse a nuevos contextos de recepción. Los relatos más famosos en Occidente proceden de dos tradiciones: la clásica (Esopo principalmente) y la india (que arranca de los jataka budistas, se consolida con el Panchatantra y se transmite gracias a Calila y Dimna). En la Edad Media relatos de ambas procedencias fueron ampliamente conocidos por su presencia en distintas colecciones $y_{1}$ en los siglos posteriores, debido a su popularidad, frecuentemente interfirieron entre si, dando lugar a falsas atribuciones, contaminaciones y versiones. En el siglo XVII el género se revitalizará gracias a La Fontaine, que conoció ambas tradiciones y popularizó muchos relatos con versiones propias. Después, otros autores tradujeron, adaptaron y versionaron a su vez estas historias. En este trabajo nos ocupamos de cómo afectaron todas estas acciones a una fábula concreta, La tortuga y los patos, comenzando por un breve repaso histórico a su origen y continuando con su recepción en traducciones, versiones y adaptaciones en castellano. Finalizaremos con el análisis de algunas reescrituras recientes destinadas específicamente al público infantil y juvenil.

Palabras clave: literatura popular, fábula, jataka, reescritura, adaptación, La Fontaine

\section{Abstract}

Fable has traditionally targeted children because of its simplicity, its characters and its didactic possibilities. It has been changing to suit new contexts of reception since its appearance. The most famous stories in the West culture come from two traditions: the classical (Aesop) and the Indian one. The latter starts with the Buddhist jataka, becomes established with the Pancatantra and is transmitted throught Kalilah wa Dimna. In the Middle Ages, stories of both origins were widely known in different collections. In the following centuries, they frequently interfered with each other, due to their popularity. This led to false attributions, contaminations and versions. In the seventeenth century, the genre revives thanks to La Fontaine, who knew both traditions and spread his own personal versions of many fables. Later, other authors translated, adapted and versioned these stories. In this work we deal with how all these actions affected a specific fable, The Tortoise and the Ducks. It starts with a brief historical review of its origin. Then it continues with its reception in translations, 
versions and adaptations to Spanish. We will finish with the analysis of some recent rewrites made for children and young people.

Key words: popular literatura, fable, jataka, rewrite, adaptation, La Fontaine.

\section{Introducción}

Las fábulas constituyen un grupo de relatos que con frecuencia e insistencia en el tiempo se ha destinado a los niños. A ello han contribuido, sin duda, dos factores de manera principal: el primero es que, como se recuerda en muchos de los trabajos dedicados al género, el término fábula es una voz equívoca (Martín, 1996: 9) y de amplio alcance, que desde sus orígenes ha servido tanto para referirse a relatos didácticos, cuyo paradigma serían las narraciones esópicas, como a otros géneros de carácter sentencioso (el refrán), narrativo (el cuento, la leyenda...) o puramente efímero (el rumor), todos ellos del gusto infantil. Ya en Juan Ruiz "encontramos el vocablo fabla para designar tanto una fábula propiamente dicha, como un dicho, un refrán, o un cuento" (Martín, 1996: 9), mientras que López de Úbeda, Lope de Vega y Cervantes la emplean como sinónimos de leyenda, rumor/hablilla y mentira respectivamente (Martín, 1996: 10) aunque, sin duda, el término más habitual es el de cuento o ejemplo, que ya aparecía en el Conde Lucanor. Junto a estos, debemos añadir el de apólogo como una de las denominaciones con mayor fortuna (Martín, 1996: 11).

A este primer factor, en que destaca el carácter popular y oral del relato ficticio, se unen otras notas que lo definen y vinculan con el público infantil y juvenil, como son el tipo de personajes preferentemente animales personificados, arquetipos de vicios y virtudes-; la sencillez y brevedad de los argumentos -reducidos al esquematismo-; la ambientación costumbrista -en espacios rurales-; su potencial para transmitir mensajes morales y didácticos - de forma explícita pero también simbólica$y$, finalmente, la maleabilidad propia de cualquier género popular para que todo lo enumerado se adapte a distintas culturas, lenguas y situaciones. Como resultado, la fábula se reinventa y actualiza como género de manera incesante, sea en prosa o en verso, dentro del sistema literario, en transmisión independiente o como parte de colecciones de relatos, en su difusión, en boca del pueblo o incluida en obras cultas e incluso en su uso (Ortiz, 2015). Ya en la Edad Media la fábula había destacado como vehículo privilegiado para diversos propósitos en ámbitos escolares:

Estas obras se estudiaban ineludiblemente en clase y los alumnos medievales se ejercitaban con ellas para aprender las materias del trivium, siguiendo una costumbre que se habia iniciado ya en el siglo II. La enseñanza medieval de la retórica tenía una vertiente práctica, en la que los escolares ampliaban, abreviaban o dramatizaban textos breves, como las fábulas. Esto explica la enorme popularidad de esta tradición y a su vez la escasa fijeza de unos textos que se guardarian en la memoria (Lacarra, 1998: 252).

C. Alvar destaca las numerosas versiones como caracteristica de este tipo de relatos y justifica su enorme difusión precisamente por la utilidad para tareas académicas: "Esta proliferación de versiones diferentes, de textos y de testimonios sólo es explicable por la popularidad de las fábulas de Esopo (y de Fedro), debido a su presencia en las escuelas como apoyo para la enseñanza de gramática y retórica en los primeros años de aprendizaje" (Alvar, 2011: 236).

En el Renacimiento este uso se mantuvo e incluso se añadió su capacidad para provocar la reflexión moral y religiosa (Arce, 2002) emparentándose con los Adagia de Erasmo. Los siglos XVIII y XIX 
supusieron la revitalización de la fábula de la mano de los ilustrados, quienes intensificaron su carácter marcadamente didáctico y moralizador (Ozaeta, 1998) en detrimento del retórico, que se ha mantenido hasta hoy, si bien en las últimas décadas decimonónicas aparece una variante genérica que podriamos denominar antifábula. Bierce (2012), con su Aesopus Emendatus, figura como uno de sus máximos representantes y abrirá nuevos caminos a una actitud transgresora que persiste en el siglo XX con Augusto Monterroso (Kleveland, 2002). En el caso del público infantil se manifiesta primero en cuentos populares (Dahl, 1989; Garner 1995) y se extiende después a las fábulas (Garner, 1996). Recientemente se han multiplicado estas nuevas lecturas (y por tanto reescrituras) que modifican no solo la forma tradicional de la fábula sino el sentido que se había fijado y transmitido con pocas alteraciones a lo largo de los siglos. Leo Lionni, con su peculiar versión de La cigarra y la hormiga en el ya clásico Frederick, es sin duda uno de los ejemplos más conocidos y exitosos destinados al público infantil.

Ahora bien, para percibir la originalidad que estas reescrituras entrañan y apreciar plenamente su potencial estético, es preciso establecer algún tipo de relación con el texto del que proceden, así como sus conexiones con otros dentro del amplio fenómeno de relaciones que mantienen las producciones artísticas y que denominamos intertextualidad. El objetivo de este trabajo reside pues en rastrear el origen, tipos y evolución del relato La tortuga y las aves para, además de reivindicar su contribución a la educación literaria de los lectores en formación, sopesar el valor de cada muestra como fábula, antifábula, contrafábula, nueva fábula o fábula al revés, a partir de la determinación del tipo y grado de mediación llevadas a cabo respecto del hipotexto de referencia.

\section{La fábula La tortuga y las aves: dos tradiciones}

A partir del siglo XV, en la literatura española como en general en la de todo el Occidente, se deja sentir un aumento del conocimiento de las fábulas grecolatinas, que añade al uso escolar la aparición de la imprenta. A partir de la edición bilingüe alemana-latina realizada por H. Steinhowel e impresa hacia 1476/1477 en UIm, se multiplicaron otras en diversas lenguas, dando lugar a numerosas colecciones en las que, junto a fábulas atribuidas a Esopo, aparecian las de Fedro o Aviano.

Paralelamente, las prensas también favorecieron la difusión de otros relatos afines a los anteriores, pero de distinta procedencia. En 1493 se imprime por primera vez en la Península una versión castellana de la colección de apólogos orientales Calila y Dimna, obra árabe de Benalmocaffa (siglo VIII). La versión castellana, conocida como Exemplario, remite al Directorium humanae vitae de Juan de Capua y contribuyó a popularizar aún más una obra que, como las fábulas esópicas, era ya sobradamente leída en la Edad Media, según nos consta por las versiones castellanas manuscritas que circulaban desde los siglos XIII (Cacho y Lacarra, 1985).

A lo largo del s. XVI, ambos grupos de relatos (los de tradición clásica y los orientales) se sintieron tan cercanos que, además de publicarse de forma independiente, coincidieron en un mismo volumen, como el impreso en 1546 en Amberes por Juan Stelsio. Las relaciones no quedaron ahí, pues como señala $\mathrm{M}^{a}$ Jesús Lacarra, la edición de Calila y Dimna presenta numerosas similitudes con el Esopete, que lectores e impresores no dejarian de advertir. La misma imprenta zaragozana de Pablo y Juan Hurus, que había preparado en 1482 y 1489 la Vida del Ysopo, será también la encargada pocos años después (1493 y 1494) de editar el Exemplario. Ambos libros comparten similar belleza formal, en xilografías procedentes de planchas alemanas importadas por el taller zaragozano [...]. Las semejanzas entre estas obras, que tienen un contenido análogo constituido por formas narrativas breves protagonizadas en su mayor parte por animales, hicieron incluso que un grabado procedente 
del Esopo se utilizara en el Exemplario y que fábulas de este último se incorporaran entre las "añadidas" en posteriores ediciones (Lacarra, 2009: 304).

Comienza aquí un fenómeno de influencias entre relatos que bien pudo haberse producido anteriormente por otros medios y en grado diverso en cada cultura pero que, gracias a la imprenta, se hizo más intenso en Occidente. En efecto, en el volumen antes indicado de Stelsio y en otros, los lectores del momento pudieron acceder al motivo que nos ocupa en forma de dos relatos con elementos en común pero que, inicialmente, se juzgaron como diferenciados. El tiempo y otros hechos los llevaron sin embargo a ofrecerse como uno solo, confluyendo en la recepción de lectores posteriores.

Conviene aclarar antes de continuar que el tipo aparece en la clasificación de Aarne-ThompsonUther con el número 225 y responde al motivo de La tortuga que quería volar; además, presenta una variante 225A, distinguiéndose dos grupos: el primero se corresponde con la narración de origen esópico "La tortuga y el águila" mientras que el segundo tiene sus raíces en un jataka budista de origen indio, "La tortuga y los gansos", conocido también, por la enseñanza que conlleva, como el jataka de "La tortuga parlanchina". Aunque el motivo de una tortuga que desea volar es común, el origen, estructura y sentido de ambos relatos permiten valorarlos como independientes, según demostraremos.

El primer grupo, de tradición esópica o clásica, ATU 225, está representado principalmente por la versión de Aviano. El hecho de que se recoja con el título de "Del galápago o tortuga y de las aves", pudo ser la causa de la confusión con el de tradición budista, titulado en algunas colecciones "La tortuga y los patos", toda vez que los jansas o gansos sagrados perdieron su excepcionalidad y quedaron como meras aves acuáticas. El texto de la tradición grecolatina es como sigue:

La II. Del galápago o tortuga y de las aues

Syn gran trabajo no puede alguno subir a las cosas altas y quanto más alto sube allende de su naturaleza, tanto más grauemente cae abaxo, como esta fabula da testimonio.

Estando todas las aues ayuntadas en vno, vino el galápago entre ellas diciendo así: Si alguna de vosotras me alçasse en alto, por cierto yo le mostraria las conchas en que se crian muchas piedras preciosas, lo qual yo no puedo por mi acabar avnque continuamente anduuiesse porque yo ando muy poco de manera que según mi andar pesado en vn día entero caminaría bien poco. Las aues oyentes este offrescimiento y prometimiento engañoso, alegres muy mucho por ello, deputaronle la águila, que es la que más alto y más presto entre ellas bola, para que lo alçasse por los ayres, donde le demandaua que le mostrasse según hauía prometido las conchas criantes las piedras preciosas. E como el galápago esto no pudiesse cumplir, la águila començo de lo apretar con sus vñas ásperas. E él gemiendo dixo así: estos tormentos no huuiesse yo descido si no huuiera demandado ser alçado suso en el ayre. E oydas estas palabras, el águila desamparó a él y cayendo en tierra fue muerto, y despedaçado al qual natura tan fuertemente huuiere armado. Amonesta esta fabula que cada vno sea contento de su estado que la natura le dio porque la soberuia pocas vezes va o llega a buen fin, mas antes pare cayda (Libro del Ysopo, 1496: 71r).

En otras versiones que derivan de fuentes afines, el título no originó tal confusión. El Libro de los gatos, traducción castellana del siglo XIV de las Parabolae o Fábulas de Odo de Cheriton (principios del siglo XIII, que ya utilizaba cuentos y fábulas para difundir la fe cristiana), se abre con "Lo que acaesció entre el galápago y el águila", relato en la línea del anterior. Las características de este 
grupo, salvando las variantes, son dos: que la tortuga representa al codicioso, que desea ascender o conseguir sus deseos sin reparar en los peligros que ello puede entrañar, y que los dos personajes son la tortuga y un águila en relación de antagonismo.

Por lo que atañe al grupo 225A, con origen en un jataka budista, llega al Calila desde el Panchatantra. Reproducimos la edición impresa más antigua, la del Exemplario, donde figura en el capítulo II de los XVII que lo componen (Del león y del buey. Y rézase del engaño y de la malicia del malsinar):

-Por cierto- dixo ella- no hay mayor enemiga en el mundo que la que el hombre tiene consigo quando no quiere conoscer a sí mismo, y tal eres tú que ni temes el peligro que tienes presente ni quieres recebir consejo de tus amigos, ni menos de tu mujer, y cahescerte ha lo que acahesció al galápago.

\section{Quien lo desestima tiene más cierto el peligro}

Moravan en una balsa un galápago con dos aves de agua entre los quales havía muy grande amistad. Fue caso que no llovió todo un verano y húvose de secar toda la balsa. Viendo las aves la grand seca deliberaron de buscar otro lugar donde podiessen tener copia de agua; y por la amistad del galápago, la qual era muy antigua, llegaron a él por ge lo poder intimar. Y él, como vio la gana que tenían de se despedir, dixoles:

- A vosotras, mis amigas, no fallesce el agua, porque con las alas en un momento la podés aver si querés, mas fallesce a mí, cuitado, que sin ella no puedo bivir. Mucho vos ruego que uséis de misericordia conmigo, y si possible es, levadme con vos dondequiera que vades.

Las aves, tuviendo piedad d’él por la luenga criança y porque no tenia forma de bivir sin el agua ni ahun quien le ayudasse para poder ir a otro lugar, le dixieron:

- A nosotras plaze mucho llevarte, y hallamos para ello un solo remedio, a saber es que tomes un pedaço de palo, y asirlo has de medio con los dientes muy reziamente, y nosotras asiremos con picos cada una de su parte del palo, y así volando te llevaremos. Mas es necesario que guardes mucho un consejo: que si andando en el aire nos vehen algunos y, maravillándose de cosa tan nueva, rien o burlan o nos echan bozes, por quanto tienes cara la vida no hables ni respondas a nadi.

Y él les ofreció fazerlo así. Y andando ya por el aire su camino todas tres en el palo, los que lo veían llamavan a bozes diciendo:

- Catad si nunca vistes galápago volar por el aire.

El galápago, de soberbio y de necio, no curando del buen consejo de sus amigas, repuso:

- Assí lo hago yo y mal vuestro grado.

Y a mala vez ubrió la boca para quererlo hablar que desasió los dientes del palo, dio consigo en el suelo y murió.

Bien conosció el macho lo que la fembra consejava, y había provado con enxemplo tan bivo qué era lo mejor y deverse apartar, mas la presumpción de no mostrar ser vencido por su mujer no le dio lugar de dexar la primera porfía, y así quedaron donde primero solian. (Haro, 2007: 119-120).

Como puede observarse, la principal diferencia reside en la enseñanza o moraleja, inherente al género fabulístico, que aqui no apunta al codicioso sino al insensato o imprudente que desatiende el consejo de sabios y amigos. En cualquiera de los casos, las advertencias no se dirigen todavía 


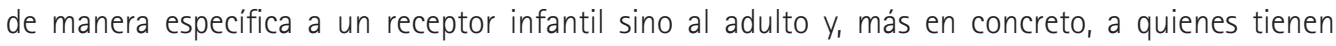
responsabilidades de gobierno.

También pensada para la educación de príncipes, no de infantes, era la lección que debía extraerse del relato tal como se popularizó en el Calila y Dimna. Esta colección de relatos guarda innegables deudas con el Panchatantra (Cacho y Lacarra, 1985: 11), obra que no fue traducida al castellano hasta 1908 y que, por lo demás, se nutre a su vez abundantemente de los jatakas budistas (Andayani, 2010: 61). En otro lugar nos hemos ocupado de los cambios que conllevó el paso de una a otra colección y no insistiremos aqui; nos limitaremos a señalar algunas diferencias formales y de sentido que permiten distanciarlo totalmente del ya visto clásico La tortuga y el águila. Gracias a que los monjes han continuado empleando estos relatos para sus predicaciones -incluso hasta la actualidad-, conocemos cómo fue la historia antes de transformarse para satisfacer los nuevos propósitos de colecciones como el Panchatantra, un espejo de príncipes.

La historia que nos interesa se encuentra dentro del Canon Pali, en el último de los "tres ( $t i)$ cestos (pitaka)" que constituyen el Tipitaka, un voluminoso corpus que sirve de Escrituras canónicas a la rama primitiva del budismo. Este tercer cesto está consagrado a los discursos de Buda y se divide a su vez en cinco colecciones o Nikâya-s, una de las cuales, la Khuddaka Nikâya, recoge entre sus quince títulos el Jâtaka, compilación de 547 relatos sobre las vidas anteriores de Buda. El que nos ocupa figura con el número 215 y resulta de los más antiguos, populares y sugerentes. Prueba de lo primero es que existan construcciones del periodo Gupta (siglos IV-VI d.C) e incluso más antiguas que en sus frisos reflejan esta historia (Vogel, 1962: 43-47); de lo segundo, que encontremos numerosas versiones en diferentes lenguas, como las populares historias de la Talkative tortoise (en lengua inglesa, que generalmente reconoce su deuda con el Panchatantra o cuentos indios) y La tortue bavarde (en francés, identificada casi siempre como jataka); de lo tercero, los relatos que actualmente emplean los monjes budistas y que actualizan o recrean esta misma historia, como el titulado La tortuga parlanchina, incluido en el bloque de reflexión sobre la sabiduría y el silencio interior (Brahm, 2015: 183-187).

Hacemos un resumen personal de la fábula en castellano a partir de la versión inglesa de Rouse (Cowell, 1895: 123-124): En uno de sus nacimientos, Buda se reencarnó como un ministro en la corte del rey de Benarés, cuya locuacidad desmedida el joven Buda deseaba corregir. Cierto dia, en un estanque próximo al Himalaya sucedió que vivía una tortuga, que entabló amistad con dos gansos salvajes (jansas), que puntualmente recabaron alli para alimentarse y que, en señal de amistad, invitaron al animal a su casa. La tortuga les preguntó el modo de ir, puesto que el lugar estaba en alto, y las aves le ofrecieron la solución con la condición de no comentarla con nadie ni abrir la boca. La tortuga aceptó y los gansos le pidieron sujetar con los dientes un palo que ellos agarraron a su vez por los extremos. De esta forma comenzaron a volar. Los muchachos de los pueblos exclamaban al verlos y la tortuga intentó reprender los comentarios. Al abrir la boca perdió el palo y cayó, casualmente, en el patio de la corte donde estaban el ya aludido rey locuaz y Buda. Ambos acudieron al lugar advertidos por los gritos de la gente y ante la visión de la tortuga, el rey preguntó al ministro qué podría haber pasado para que de repente apareciese alli tal criatura. Buda vio la esperada oportunidad para reprender al rey y respondió con su propia versión de lo narrado: "Seguramente, la tortuga y los patos eran amigos y querían que los acompañara, para lo cual se habrá colgado de un palo; entonces, cuando estaba en el aire, habrá oído algo y con el deseo de intervenir, lo ha perdido. Así pues, por no haber tenido la boca cerrada, se habrá caído, perdiendo la vida. Eso fue lo que habrá pasado". Y añadió: "Esto es lo que tiene hablar en exceso y este el desgraciado final al que puede conducir", concluyendo con unos versos. 
Como se observa, no es la codicia lo que este jataka desea censurar, como en la tradición grecolatina, ni tampoco la insensatez, como en la versión del Calila, sino exclusivamente el vicio de la locuacidad o la charlatanería, que enlaza con la importancia del silencio para la reflexión, el autoconocimiento y el diálogo (propio y con Dios).

\subsection{La fusión de La Fontaine}

La publicación en 1679 de las 87 fábulas de La Fontaine correspondientes a los libros IX a $\mathrm{XI}$ supuso un cambio en la andadura de los relatos vistos, que se fusionaron en uno solo. El escritor conocía tanto la tradición esópica -seguramente de primera mano- como la oriental, gracias a la traducción al francés de una versión persa del Calila, difundida como Livré des lumières, ou la conduite des roys, composé para le sage Pilpay, indien, (Sahid, 1644: 124-126), pero no el jataka que estaba en la base -aunque su intuición le hizo potenciar algunos elementos de este-, por lo que creó una versión tan original que llega a escandalizar: "The geese have become ducks! In the French poem there is nothing reminiscent of its Indian origin. The initiative of the aerial journey of the three animals is atribuited to the light-headed tortoise, qui, lasse de son trou, voulut voir le pays" (Vogel, 1962: 45). La cuestión es que La Fontaine no tenía como referencia el jataka, sino uno de los múltiples resultados de traducciones y adaptaciones, plasmado en el Calila y que remitía a una de las numerosas versiones del Panchatantra. La Fontaine consideró necesario exhibir su conocimiento de fábulas clásicas y particularmente, en estos últimos libros, recriminar algunos vicios propios de la sociedad del momento y, como recuerda Dido (2009: 3), el francés no escribía pensando en un receptor infantil cuando creaba versos como los de su fábula 2 del Libro $X$ :

\section{LA TORTUE ET LES DEUX CANARDS}

Une tortue était, à la tête légère,

Qui, lasse de son trou, voulut voir le pays,

Volontiers on fait cas d'une terre étrangère:

Volontiers gens boiteux haïssent le logis.

Deux Canards à qui la commère

Communiqua ce beau dessein,

Lui dirent qu'ils avaient de quoi la satisfaire:

Voyez-vous ce large chemin?

Nous vous voiturerons par l'air en Amérique.

Vous verrez mainte république,

Maint royaume, maint peuple; et vous profiterez

Des différentes mœurs que vous remarquerez.

Ulysse en fit autant. On ne s'attendait guère

De voir Ulysse en cette affaire.

La tortue écouta la proposition.

Marché fait, les Oiseaux forgent une machine

Pour transporter la pèlerine.

Dans la gueule en travers on lui passe un bâton.

"Serrez bien, dirent-ils; gardez de lâcher prise."

Puis chaque Canard prend ce bâton par un bout.

La Tortue enlevée on s'étonne partout

De voir aller en cette guise 
L'animal lent et sa maison,

Justement au milieu de l'un et l'autre Oison.

"Miracle! criait-on; venez voir dans les nues

Passer la reine des tortues.

-La reine! vraiment oui; je la suis en effet;

Ne vous en moquez point." Elle eût beaucoup mieux fait

De passer son chemin sans dire aucune chose;

Car lâchant le bâton en desserrant les dents,

Elle tombe, elle crève aux pieds des regardants.

Son indiscrétion de sa perte fut cause.

Imprudence, babil, et sotte vanité,

Et vaine curiosité,

Ont ensemble étroit parentage.

Ce sont enfants tous d'un lignage

(La Fontaine, 1940: 191-192)

Un análisis comparado de este texto con sus modelos anteriores revela que, respecto a los personajes, La Fontaine se mantuvo fiel a la tradición oriental y en lugar de un águila eligió dos aves -coprotagonistas y no antagónicas a la tortuga- que, contextualizadas al espacio y cultura europeas, aparecen como patos, según ya había sucedido en el Calila.

El motivo para el viaje o la elevación lo toma sin embargo de la tradición clásica esópica en la versión de Aviano y no hay necesidad provocada por sequía alguna. La tortuga desea ver mundo y elevarse, obviando su condición terrestre, por lo cual ofrece a las aves tesoros a cambio de su colaboración. La Fontaine elimina el trato y añade una expansión del capricho de viajar, centrada en la personalidad de la tortuga, que responde al contexto social del propio La Fontaine y al afán imperialista de Europa en el siglo XVII, lo que le da mayor juego en la enseñanza moral. Incluye también en esta amplificación referencias a Hércules como exponente de personaje aventurero.

En consecuencia con lo anterior, por lo que atañe a las condiciones que se imponen previas a la elevación, el francés sigue la tradición oriental. Las advertencias aparecen explícitas en boca de las propias aves, que mantienen la sabiduría de los jansas y prevén las consecuencias. En el caso de la tradición clásica, por el contrario, no existían tales condiciones puesto que la precipitación no era causa del descuido sino del castigo intencionado del águila. El motivo de la caída se vincula en ambas tradiciones a los defectos de la tortuga pero estos no coinciden. En la vertiente clásica, es la codicia y soberbia de quien pretende ser lo que no le corresponde, incluso sirviéndose de la mentira y la manipulación, mientras que los relatos derivados del jataka budista mantienen -en diverso grado- el hecho de "abrir la boca" como causa real de la caída, aunque la razón primera (la pura charlatanería o incontinencia verbal para responder a los comentarios) se presenta con cierta ambigüedad, aprovechada por La Fontaine para sugerir, en lugar de una sola razón de escarmiento, una constelación de defectos "emparentados". En cualquier caso, se mantiene preferentemente la línea oriental.

El propósito moral de la fábula se deriva de la caracterización previa de los personajes así como de la sucesión de acciones antes vistas y sus consecuencias. Este elemento, que garantiza al género fabulístico su aceptación en nuevos contextos de recepción, es esencial en la versión del francés pues, a partir de las características de su propio entorno, arremete contra algunos de los vicios 
favoritos en los ilustrados: la vanidad, la charlatanería, la presunción..., insinuando interrelaciones y dependencias naturales. Todavía se tardarán siglos en reconocer la singularidad del receptor infantil pero la actualización de los defectos y la efectividad del verso permitió que los traductores y escritores (como Samaniego), vieran en la simbiosis de La Fontaine una mezcla idónea para unos destinatarios (los niños y jóvenes) que comenzaban a adquirir protagonismo.

\subsection{Traducciones, adaptaciones, versiones y reescrituras para niños antes del siglo XX}

En el siglo XVIII, dentro de la corriente ideológica de la Ilustración, muchos escritores vieron en la fábula un vehículo privilegiado para reflexionar sobre los problemas morales y sociales que les preocupaban, enfatizando así la función didáctica del arte y posibilitando que este llegase a todo tipo de público. En este contexto se explican la multitud de versiones y actualizaciones que se llevaron a cabo, particularmente de las fábulas clásicas, a partir de traducciones y adaptaciones previas de Esopo o bien de las versiones que La Fontaine había popularizado en el siglo anterior (Ozaeta, 2001). En un momento en que comienza a reconocerse la singularidad de los niños y sus necesidades específicas en lo que concierne a las lecturas, reaparece la figura del mediador como esencial para que estos textos, aparentemente sencillos pero de un potencial extraordinario en lo que a las intenciones didácticas se refiere, lleguen, con la adecuada interpretación y la calidad estética deseable, a un lector poco formado; de ahí la proliferación de traducciones, adaptaciones y, finalmente, nuevas versiones de las viejas fábulas. Es en este siglo cuando el género, que hasta ahora había tenido un carácter didáctico (educativo, moralizante) añade la utilidad pedagógica, convirtiendo al niño en su principal destinatario; para ello se produce una selección de textos y una adaptación de los mismos que responde a las intenciones de los adultos (mediadores) en cada momento histórico.

Samaniego, nuestro escritor paradigmático en el género, es pionero en explicitar esta voluntad de mediación que afecta, en primer lugar, a la lengua $y$, en segunda instancia, al estilo, pues la moraleja es algo que no contempla alterar, dada la veneración que en esta época se sentía por la tradición clásica. Respecto a lo primero, Samaniego confiesa en el Prólogo que se decide por el verso y el castellano atendiendo a las características de los receptores, muchachos a los que causa deleite "un cuentecillo adornado con la dulzura y armonía poética, y libre para ellos de las espinas de la traducción, que tan desagradablemente les punzan en los principios de su enseñanza" (Samaniego, 1781: s.p.). Da cuenta el autor de la libertad con que unos fabulistas se sirven de los relatos de otros y justifica así el uso (o abuso) que pueda él mismo hacer de sus modelos; respecto al estilo, añade que: "Si en algo he empleado casi nimiamente mi atención, ha sido en hacer versos fáciles hasta acomodarlos, según mi entender, a la comprensión de los muchachos" (Samaniego, 1781: s.p.). Así pues, Samaniego se declara mediador en dos aspectos: como traductor (al emplear el castellano) y como adaptador (haciendo versos fáciles), al tiempo que reconoce entre sus modelos a Esopo, Fedro y La Fontaine. Su ignorancia de la tradición fabulistica medieval española se revela, como en otros casos, en el que nos ocupa, pues su versión El águila y la tortuga (Fab. XI del Libro IV) sigue la línea de Esopo y Aviano, sin hacerse eco de las novedades incluidas por el fabulista francés. Incluso reproduce la moraleja del traductor Pedro Simón, del siglo XVI: "Para que así escarmiente/ quien desprecia el consejo del prudente" (Samaniego, 1781: 125).

Idéntica labor de mediadores realizaron tres traductores tempranos de La Fontaine que dieron a conocer la obra completa, pues en las selecciones y antologías raramente figura la fábula que nos ocupa. El primero de ellos fue Bernardo María de la Calzada, en 1787, a los que siguieron Lorenzo Elizaga y Teodoro Llorente y Olivares en 1883 y 1885 respectivamente. Este último es el único que 
decide servirse de la prosa y abandonar el verso que, con más o menos acierto artístico, habian conservado los otros dos. Por lo demás, pocas diferencias tienen estos productos, respetuosos al indicar que son traducciones y también en el contenido, si bien acomodan a su gusto la moraleja, abundando en los defectos de la tortuga de forma distinta, según puede verse, pues Bernardo María de la Calzada añade la suficiencia y enfatiza la charlatanería, mientras que Elizaga no alude a este último defecto y destaca la curiosidad, incluida por Llorente pero que Calzada no menciona. Se diferencian también en la metáfora que expresa la relación entre los defectos, con aires exclusivamente "familiares" en Calzada y Elízaga y con un añadido "natural" en Llorente:

\author{
La Fontaine \\ Imprudence, babil, et sotte vanité, \\ Et vaine curiosité, \\ Ont ensemble étroit parentage. \\ Ce sont enfants tous d'un lignage.
}

B. M. de la Calzada

La charlatanería, la imprudencia, la necia vanidad, la suficiencia, y todas las empresas, que son vanas, por lo común van juntas como hermanas (La Fontaine, 1787: 211)

\author{
L. de Elízaga \\ La curiosidad ociosa, \\ la vanidad, la imprudencia. \\ Son de la misma familia \\ y muy cercanas parientas \\ (La Fontaine, 1883: 436)
}

Estas traducciones de La Fontaine dieron lugar a adaptaciones castellanas en los siglos siguientes, especialmente la de Llorente pero, en cambio, son escasas las que encontramos en esta época de relatos para niños basados en la tradición oriental, tal como figuraba en el Calila, el Panchatantra o el jataka budista.

Por lo que se refiere al relato de tradición esópica, a principios del XIX es posible encontrar en el mundo anglosajón, junto a la insistencia en traducciones y adaptaciones, autores que reescriben las historias de forma más libre y personal, especificamente destinadas a los niños, como Jefferys Taylor, que incluye humor, fantasía y cierta extravagancia en su Aesop in rhyme. Estas libertades encontraron su continuación en el mordaz A. Bierce y su Aesopus Emendatus, cuyo título anticipa el contenido transgresor de la lectura tradicional. En la Fab. XLIV, Taylor (1828: 68-69) ofrece su peculiar versión de la historia de la tortuga que queria volar que, sorprendentemente, no está en Bierce. Obras con este carácter no existen, hasta donde alcanzamos, en España, que continúa con lecturas morales y didácticas en la línea de Samaniego hasta finales del XX, si exceptuamos las peculiares versiones (ofrecidas sin embargo como traducciones directas de Esopo) de Eduardo de Miér. Si bien la fábula LII, "La tortuga y el águila" presenta con pocas modificaciones la historia de tradición esópica, en la fábula CCCV, "La tortuga y los dos cuervos", Miér (1871: 178-179) remite (sin indicarlo) a la línea oriental al presentarnos a una tortuga con caracteristicas similares a la de La Fontaine ("algo ligera de cascos y de carácter veleidoso") y con idénticos motivos para viajar ("cansada ya de su monótona existencia") que comunica su propósito de volar a dos cuervos en lugar de patos. Son estos los que se muestran dispuestos a complacer a su amiga y se proveen de un junco. El resto del relato es idéntico al de La Fontaine, incluyendo que es la respuesta de la tortuga a la gente cuando la califican de "reina" lo que provoca la caída. También es casi literal la moraleja: "La imprudencia, la charlatanería y la vanidad tienen un estrecho parentesco y son hijas de un mismo linaje". 


\subsection{Traducciones, adaptaciones, versiones y reescrituras para niños a partir del siglo $\mathrm{XX}$}

En el siglo XX la fábula se reinventa. De nuevo es el mundo anglosajón donde se producen peculiares versiones de las historias y en España, con la excepción de las reescrituras de intencionalidad política de Antoniorrobles (Chicote, 2006), habrá que esperar a los años 80 para encontrar, con la llegada de la democracia, las "otras fábulas", dedicadas a niños. Una clara conciencia de que los niños de ahora no son como los de antes, principalmente por la globalización y el acceso a la información que permiten las tecnologías, lleva a autores a cambiar, reescribir y dar una nueva interpretación a las fábulas. En España Miguel Ángel Fernández-Pacheco ha escrito varias refábulas o fábulas al revés y en Hispanoamérica son varios los autores de literatura infantil y juvenil que han entendido la reescritura de estos relatos como una renovación del género, siguiendo la línea marcada por Monterroso si bien, de forma general, en el siglo XX continúan las adaptaciones de corte tradicional de fábulas esópicas. Por lo que se refiere al Calila, las ediciones destinadas específicamente a los niños son relativamente recientes. Debemos destacar, por pionera como en otros aspectos, la selección de treinta y tres cuentos que realiza Carmen Bravo-Villasante partiendo de la base de que su lectura le gustará tanto al niño "que luego irá al gran libro del Calila y Dimna para leer todos los cuentos, más de setenta y cinco, alli incluidos" (Calila y Dimna, 1990: 12). Esta selección, entre otros méritos, tiene el de mencionar explícitamente el origen de los relatos, así como su autor y vinculación con otras colecciones. El cuento de "Los dos ánades y el galápago" (Calila y Dimna, 1990: 48-50) se corresponde con el texto manuscrito que editó Lacarra de la traducción alfonsi y, por lo tanto, carece de moraleja explícita, invitando con el final abierto "Ya he entendido lo que dijiste" a la reflexión sobre el relato, que conecta más con la educación literaria tal como se entiende hoy, al permitir la participación activa del receptor infantil como agente que dota de significado al texto. Esta adaptación es bastante fiel y se limita a una modernización del lenguaje, a diferencia de otras ediciones posteriores.

La selección de M. Teresa Caso, Calila y Dimna. Cuentos y fábulas para niños, no se limita a las habituales tareas consistentes en la actualización lingüística y reducción (Sotomayor, 2005) sino que los hombres del texto original son convertidos en "conejos curiosos", con lo cual el relato es casi plenamente un cuento de animales; la moraleja está explícita y se aproxima al Exemplario, incluso en el contenido, sobre lo inconveniente que resulta no hacer caso de los consejos de los amigos, con lo que la participación del receptor se ve más condicionada y dirigida. Otra licencia que se toma la adaptadora es la dulcificación del final, por lo que la tortuga, al hablar y perder el palo, cae "patas arriba sobre un prado, quedando llena de golpes y dolorida" (Caso, 2012: 16) pero no muere; hay simple escarmiento por lo tanto y la posibilidad de una segunda oportunidad tras el aprendizaje.

La tercera adaptación de interés es la de Rocio Martínez (2015). Lo más novedoso es su forma de álbum ilustrado, un género de gran aceptación entre el público infantil. Aunque está presente el marco que caracteriza la obra de referencia, las narraciones se ofrecen como autónomas y los elementos gráficos, de gran belleza y coherencia con el contenido, contribuyen poderosamente a la interpretación de los relatos (generalmente en interacción complementaria entre texto/imagen), como cabia esperar en un álbum ilustrado. La acción adaptativa más frecuente es también la reducción, muy notable dado el refuerzo que suponen los elementos gráficos, a la que añade acciones aclaratorias y explicativas, como la caracterización de la tortuga como "muy charlatana", que enlaza con los jataka pero no estaba en el Calila. La enseñanza, como en la adaptación de Bravo-Villasante tampoco está explícita y permite al lector sacar sus propias conclusiones. 
Una cuarta adaptación, que a diferencia de las anteriores ofrece el texto completo de la colección, es la de José Maria Merino (Calila y Dimna, 2016), que se sirve de los textos fijados por otras ediciones (que menciona) y moderniza el lenguaje; no ejerce de traductor, como tampoco lo hacian las anteriores.

Finalmente, cabe añadir, por lo singular, una colección de relatos titulada Fábulas de animales, selección de A. Jané que también incluye el relato que nos ocupa bajo el título "Los patos y el sapo" (Jané, 1992: 11-14). Se presenta como historia independiente, sin mencionar la fuente (ni Esopo ni Calila) y textualmente se ciñe a la tradición oriental, excepto en el hecho de que la tortuga es un sapo (como en algunas versiones rusas) y explícitamente se indica que este responde y pierde el palo por pura vanidad:

El sapo, orgulloso de la admiración que despertaba, no pudo contenerse y contestó:

- ¡Palurdos! ¡Qué poco mundo habéis visto!

Y al decir esto, como tuvo que abrir la boca, cayó al suelo, se estrelló y se fue directo al otro barrio. (Jané, 1992: 14).

Por lo que se refiere a nuevas fábulas, la escasa difusión del relato hace que también las reescrituras sean escasas, si lo comparamos con las que existen de otras historias, como La cigarra y la hormiga o La lechera. En el ámbito hispanoamericano, que es donde han tenido más fortuna estas nuevas fábulas, contamos, al menos, con dos reescrituras que responden a hipotextos y propósitos bien distintos.

"La tortuga y los patos", de Beatriz Barnes (1989), es un cuento de corte específicamente infantil, que remite claramente a La Fontaine, con el que coincide en elementos básicos: se trata de una narración independiente protagonizada por dos patos y una tortuga caprichosa de conocer mundos lejanos; la idea de volar es de los patos y le advierten que no abra la boca; muestra orgullo como "Reina" y, finalmente, cae. A partir de aqui, la autora realiza estrategias adaptativas de tipo expansivo, que caracterizan a los personajes y permiten, con algunas modificaciones del argumento, cambiar la moraleja. La protagonista se presenta como alguien sensible, que a pesar de que "le gustaba mucho viajar", nunca habia podido hacerlo, sea por ayudar a otros ("apareció Doña Rata con sus seis hijas a pasar las vacaciones en su casa"), enfermedad ("una angina que la mantuvo en cama durante todo el verano") o su edad ("era muy chiquita para viajar sola"). Es también una persona ambiciosa ("hubiera querido tener alas para volar") que, sin embargo, desprecia lo que le rodea ("pensaba que, como aquellas cosas estaban tan cerca, no valían la pena de moverse para ir a verlas"). Sus virtudes hacen que al comunicar la voluntad de ver mundo a los patos, estos, sin que la tortuga lo solicite, se ofrezcan a llevarla ("Doña Tortuga, hemos decidido una cosa"), provocándole la lógica felicidad ("Doña Tortuga no cabía en si de alegría") pero sus defectos, focalizados en el desprecio a su entorno ("-iSí, soy la reina de las tortugas y me voy a otros paises porque aqui no hay nada que merezca ser visto por mí!") merecen un castigo, de forma que la tortuga cae en mitad de la laguna. Como sucedía en la adaptación de Caso, aquí también se dulcifica el final y la tortuga no muere, posibilitando así esa segunda oportunidad que todo aprendizaje conlleva y que le servirá, una vez que es socorrida por los otros animales, para descubrir en su convalecencia el valor de lo propio: "-Esto es tan lindo como los volcanes, las góndolas y los ascensores que hay en los lejanos países"-. La tortuga sustituye sus deseos de viajar por el conocimiento del entorno y la autora justifica su "error" como cierre del relato, por su corta edad, en un guiño a los receptores: "Menos mal que le quedaban todavía ciento cuarenta y cinco 
años por delante, porque todo lo anterior le ocurrió a Doña Tortuga cuando era aún muy chiquita, y no sabia ver, ni apreciar bien todo lo bueno, y hermoso, y lindo, que la rodeaba."

Muy distinto, el relato "La intención de la tortuga" de M. Birmajer, incluido en sus Fábulas salvajes, (2006). El autor advierte en la contraportada: "Ojalá mis maestros Esopo, La Fontaine y Samaniego aprobaran estas Fábulas salvajes. Una o dos de ellas son irrespetuosas reescrituras, con final y desarrollo distinto de las que ellos mismos escribieron. Aunque no creo que de la literatura puedan desprenderse enseñanzas morales, no he podido librarme de la tentación de sumergir a algunos de mis animales en el cenagoso río del debate sobre qué está bien y qué está mal. Por eso creo que estas páginas pueden ser especialmente atractivas para los adolescentes y los jóvenes, porque es la época de nuestra vida en que buscamos, con algo de salvajismo, nuestro camino moral". La historia se presenta como independiente y, alejada de La Fontaine, da una vuelta de tuerca a la tradición clásica (Esopo y Samaniego) al hacernos pensar sobre la legitimidad de soñar y tener aspiraciones, así como el sentido real de la vida, y la duda sobre permanecer en lo seguro y confortable o aceptar la incertidumbre y el riesgo que comporta perseguir los sueños y luchar por ellos. El deseo de volar no es en la tortuga doméstica de Birmajer algo que deba reprobarse sino, al contrario, una necesidad intima muy humana, una aspiración noble por superarse y convertirse en lo que se desea ser. Se entiende que por lograr este sueño la tortuga esté dispuesta a morir. Birmajer localiza la acción en un entorno urbano y la tortuga vive en una terraza acogida por una familia y supervisada, en su tristeza, incluso por un veterinario. El papel de "águila" lo representan dos palomas (en esto sigue a La Fontaine, lo mismo que en servirse de un palo) que, viendo la tristeza en que vive la tortuga, deciden ayudarla, pero esta no muere por charlatana sino porque, de forma natural, le faltan las fuerzas una vez que es elevada por el sabido mecanismo. Cuando, ante la caída, los pichones recuerdan a su amiga que le advirtieron de que su deseo podía costarle la vida, la tortuga responde con unas emotivas palabras. Cuatro veces les había repetido de forma machacona a sus compañeras la frase "Quiero volar", hasta convencerlas a pesar de lo absurdo de su petición, y cuando la tortuga agoniza sobre el asfalto, los pichones parecen querer librarse de un sentimiento que mezcla culpa, responsabilidad y dolor, recordándole la advertencia: "-Oh, necia, necia- dijo un pichón-, ite dijimos que volar no era para tortugas! ¡Mira lo que has hecho con tu larga vida!". La tortuga, mientras agoniza, acepta su destino reafirmándose en unos deseos que conectan con la voluntad caprichosa de los niños y el impetu irreflexivo de los adolescentes, ignorantes ambos del peligro que puede traerles la vida. Ante ello, afirma con un candor que emociona: "-Pero yo quería volar- dijo la tortuga con su último suspiro-, no una larga vida" (Serrano, 2004: 196).

\section{Conclusiones}

Bajo el motivo de la tortuga que quería volar es posible recoger relatos que responden a dos tradiciones distintas. En Occidente confluyen e interactúan entre sí a partir de la Edad Media gracias a la imprenta, que populariza obras que hasta ese momento eran bien conocidas y empleadas en diversos ámbitos pero tenían alcance más limitado. Es el caso de las fábulas esópicas, usadas para estudios de latín, retórica y oratoria y también el de los apólogos orientales que servían para la educación de nobles.

A partir de finales del siglo XV y después, en el XVI y XVII, el motivo de la tortuga que quería volar se popularizó principalmente en las colecciones que remitían a fábulas esópicas (en la variante de La tortuga y el águila o como La tortuga y las aves de Aviano) y también, en menor medida, con las traducciones en diversas lenguas europeas de la obra de Benalmocaffa, Calila y Dimna. El interés 
que mostró La Fontaine por unos y otros relatos le llevó a realizar, a partir de sus propias lecturas, una nueva versión, "La tortuga y los patos", que seleccionaba y fusionaba elementos de ambas líneas; la genialidad del francés consiguió que su texto se difundiese ampliamente en los siglos XIX y XX, gracias a las numerosas traducciones y adaptaciones que se hicieron en el ámbito hispánico. Coincide el momento con el surgimiento de la literatura infantil y juvenil, por lo que la fábula, que hasta ahora habia formado parte de la literatura ganada, en palabras de Juan Cervera, o aquella que los niños habian asumido como propia de acuerdo a sus intereses, pasa a ser propiamente literatura infantil, cuando los escritores encuentran en este género un vehículo de expresión personal en sus producciones destinadas a los niños, con modificaciones de diverso grado. Resultan marginales y escasas, en comparación con las que remiten al modelo de La Fontaine, las obras infantiles a partir de la línea clásica (como la realizada por Samaniego), o las selecciones y adaptaciones de cuentos del Calila y Dimna (que solo comienzan a encontrarse en las últimas décadas).

La renovación de la fábula como género a finales del siglo XX y el éxito de algunas reescrituras de cuentos tradicionales destinadas a los niños, también han contribuido, a su vez, a enriquecer el repertorio de obras destinadas al joven receptor. Las denominadas nuevas fábulas constituyen un fenómeno, particularmente visible en Hispanoamérica, sustentado en el hecho de que la fábula, como los cuentos tradicionales, constituyen un hipotexto leído, legible o al menos reconocible (Díaz, 2003: 65), de ahi su potencial para provocar en el receptor respuestas personales y actitudes positivas ante la lectura. No obstante, la exigencia de conocer la fábula de referencia también es un condicionante, lo que explica las pocas muestras de nuevas fábulas para niños a partir del motivo de La tortuga que quería volar, en comparación con el éxito de otros relatos de este mismo género. Las dos que conocemos, de B. Barnes y M. Birmajer, remiten a la versión más difundida de La Fontaine y a la clásica de Esopo, respectivamente, ofreciendo como principal novedad la consideración de las características del lector, que lleva a una dulcificación del final en el primer caso y a plantear aspectos de interés, como el idealismo en otro.

En conclusión, la fábula como género se mantiene hoy entre los preferidos tanto de jóvenes lectores como de escritores que lo toman como referencia cuando se dirigen al público infantil, potenciándose en la recepción actual no solo las intenciones didácticas y morales que tradicionalmente se le habian atribuido sino principalmente su capacidad para adaptarse a las culturas y permitir el deleite actualizando los mensajes con el paso de los siglos. El motivo de la tortuga que quería volar es un buen ejemplo de ello.

\section{REFERENCIAS BIBLIOGRÁFICAS}

Aesopi fabvlae latine atq. Hispane scriptae quaq. Fieri protuit diligentia fidelitateq. E Graeca lingua induas has traductae... interprete Petro Simone Aprileo. (1575). Zaragoza, Michaelis Huessa.

ALVAR, C. (2011). El retrato de Esopo en los Isopetes incunables: imagen y texto, Revista de Filología Española-RFE, XCl, (2), 233-260.
ANDAYANI, A. (2010). Story motif variety in Pancatantra indian fable, Parafrase, 10, (2), 61-71.

ARCE, F. de (2002). Adagios y fábulas. Ed. de A. Serrano Cueto, Madrid: Instituto de Estudios Humanísticos.

BARNES, B. (1993). Fábulas para leer en voz alta. II. Marta Gaspar. México: CEAL (Salvat-SEP). Publicado anteriormente en fascículos, en Libros del Rincón, en 1989. 
BIERCE, A. (2012). Fábulas feroces. Trad. de Aitor Ibarrola-Armendariz. Madrid: Alianza Editorial. Ed. original Fantastic Fables, 1899.

BIRMAJER, M. (2006). Fábulas salvajes. Buenos Aires: Alfaguara Infantil. $1^{\text {a }}$ ed. en Buenos Aires: Sudamericana, 1996.

BRAHM, A. (2015). La vaca que lloraba y otros cuentos budistas acerca de la felicidad. Barcelona: Kairós.

CACHO, J. M. Y LACARRA, $M^{a}$ J. (eds.) (1985). Calila e Dimna. Madrid: Castalia.

Calila y Dimna (1990). Prólogo, selección y versión de Carmen Bravo-Villasante. Palma de Mallorca: José J. de Olañeta, Biblioteca de Cuentos maravillosos 55

Calila y Dimna (2016). Ed. de José María Merino. Madrid: Páginas de Espuma.

CASO, Ma T. (adap.) (2012). Cuentos y fábulas para niños. Calila y Dimna. Barcelona: Nobel.

CHICOTE, G. B. (2006). Fábulas para la guerra: reformulación de literatura ejemplar en propaganda política. Olivar, 7(8), 153-163. Consultada el 12 de enero de 2018, http://www.scielo.org.ar/scielo. php?script=sci_arttext\&pid=S1852 44782006000200010 \&tIng=es\&t|lng=es.

COWELL, E. B. (ed.) (1895). The jātaka or stories of the Buddha's former births, Vol. II, trans. By W. H. D. Rouse, Cambridge: University Press. Consultada el 12 de enero de 2018, https://archive.org/stream/ jatakaorstorieso02cowe\#page/122/ mode/2up

DAHL, R. (1989). Cuentos en verso para niños perversos. Madrid: Alfaguara. Ed. original en 1982: Revolting rhymes.

DÍAZ ARMAS, J. (2003). Aspectos de la transtextualidad en la Literatura Infantil. En Mendoza, A. y Cerrillo, P. C. Intertextos, aspectos sobre la recepción del discurso artístico (pp. 61-98). Cuenca: UCLM.

DIDO, J. C. (2009). Teoría de la fábula, Espéculo, 41, Consultada el 24 de septiembre de
2018, https://webs.ucm.es/info/especulo/ numero41/fabula.html

GARNER, J. F. (1995). Cuentos infantiles politicamente correctos. Barcelona: Circe. Ed. original en 1994: Politically Correct Bedtime Stories.

GARNER, J. F. (1996). Más cuentos infantiles políticamente correctos. Barcelona: Circe. Ed. original en 1995: Once upon a more enlightened time.

HARO, M. (ed.) (2007). Exemplario contra los engaños y peligros del mundo. Valencia: Universidad.

JANÉ, A. (1992). Fábulas de animales. II. Juan Ramón Alonso. Zaragoza: Edelvives, Col. Ala Delta 106. (2ª ed.; 1ª: 1990).

KLEVELAND, A. K. (2002). Augusto Monterroso y la fábula en la literatura contemporánea. América Latina Hoy, 30, 119-155.

LA FONTAINE, J. de (1787). Fábulas. Trad. de Bernardo María de la Calzada, tomo II, Madrid: Imprenta Real.

LA FONTAINE, J. de (1883). Fábulas. Trad. de Lorenzo de Elizaga, París/México: Ch. Bouret.

LA FONTAINE, J. de (1940). Fábulas. Trad. de Teodoro Llorente, Barcelona: Montaner y Simón.

LACARRA, Ma J. (1998). El libro de Buen Amor, ejemplario de fábulas a lo profano. En Paredes, J. y Gracia, P. (eds.). Tipología de las formas narrativas breves románicas medievales (pp. 237-252). Granada, Universidad.

LACARRA, Ma J. (2009). Fábulas y proverbios en el Esopo anotado. Revista de poética medieval, 23, 297-329.

Libro del Ysopo: famoso fablador, historiado en romançe (1496), Burgos: Fadrique Alemán de Basilea. Consultada el 12 de enero de 2018, http://gallica.bnf.fr/ark:/12148/ bpt6k8541711/f10.image. $r=y s o p o$

MARTíN, F. (1996). Antología de fábulas esópicas en los autores castellanos. Cuenca: UCLM. 
MARTÍNEZ, R. (adap.) (2015). Del maravilloso mundo de Calila y Dimna. Barcelona: Thule.

MIÉR, E. de (1871). Las fábulas de Esopo. Traducidas directamente del griego, y de las versiones latinas de Fedro, Aviano, Aulo Gellio, etc. Madrid: José Astort y Compañía.

ORTIZ, A. Ma. (2015). Actualización didáctica de las fábulas: la integración de aprendizajes lingüísticos y literarios desde una perspectiva pragmática. Lectura y signo: revista de literatura, (10), 1, 127-139.

OZAETA, Ma R. (1998). Los fabulistas españoles (con especial referencia a los siglos XVIII y XIX), Epos: Revista de filología, 14, 169205.

OZAETA, Ma R. (2001). Traducciones y adaptaciones al castellano de las fábulas de La Fontaine en el siglo XX. En Lafarga, F. y Dominguez, A. (coords.) Los clásicos franceses en la España del siglo XX: estudios de traducción y recepción (pp. 163-173), Barcelona: PPU.

SAHID, D. (trad.) (1644). Le livre des lumières sur la Conduite des rois, compose par le sage Pilpay indien. Paris: Simeón Piget. Consultada el 12 de enero de 2018, https:// fr.wikisource.org/wiki/Livre:Gaulmin_-_ Livre_des_lumi\%C3\%A8res,_ou_la_ Conduite_des_roys,_1644.djvu

SAMANIEG0, F. Ma. (1781). Fábulas en verso castellano..., Valencia: Benito Monfort. Consultada el 12 de enero de 2018, http://www.cervantesvirtual.com/obravisor/fabulas-en-verso-castellano-parauso-del-real-seminario-vascongado--0/ html/ff18576c-82b1-11df-acc 7002185ce6064_3.html\#I_74_

SERRANO, Ma de los Á. (sel.) (2004). Caminos de la fábula. Antología. Buenos Aires: Ediciones Colihue.

SOTOMAYOR, Ma V. (2005). Literatura, sociedad, educación: Las adaptaciones literarias. Revista de Educación, núm. extraordinario 1, 217-238.

TAYLOR, J. (1828). Aesop in rhyme with some originals. London: Baldwin and Cradock.

VOGEL, J. P. (1962). The Goose in Indian Literature and Art. Leiden: E.J. Brill. 